\title{
Responses to surgical stress after esophagectomy: Gene expression of heat shock protein 70, toll-like receptor 4, tumor necrosis factor- $\alpha$ and inducible nitric oxide synthase
}

\author{
SATOSHI SUZUKI $^{1}$, HIROSHI MORIMATSU ${ }^{1}$, EMIKO OMORI ${ }^{1}$, HIROKO SHIMIZU ${ }^{1}$, \\ TORU TAKAHASHI ${ }^{1}$, TOMOKI YAMATSUJI ${ }^{2}$, YOSHIO NAOMOTO ${ }^{2}$ and KIYOSHI MORITA ${ }^{1}$ \\ Departments of ${ }^{1}$ Anesthesiology and Resuscitology, and ${ }^{2}$ Gastroenterological Surgery, \\ Transplant and Surgical Oncology, Okayama University Graduate School of Medicine, \\ Dentistry and Pharmaceutical Sciences, Okayama 700-8558, Japan
}

Received April 20, 2010; Accepted July 5, 2010

DOI: $10.3892 / \mathrm{mmr} .2010 .335$

\begin{abstract}
The progression and interrelationship of mediators that are released, activated or suppressed after major surgery appear to play an important role in responses to surgical stress. Heat shock protein 70 (HSP70) is stress-induced and acts like a cytokine to modulate pro-inflammatory mediators, such as tumor necrosis factor- $\alpha$ (TNF- $\alpha$ ) and inducible nitric oxide synthase (iNOS), by stimulating toll-like receptor 4 (TLR4) signaling. We hypothesized that this effect would occur after major surgery, such as esophagectomy. We therefore measured the expression of HSP70, TLR4, TNF- $\alpha$ and iNOS mRNA in peripheral blood mononuclear cells (PBMCs) from 11 patients who underwent esophagectomy with thoracoabdominal procedures at postoperative day (POD) 1 and POD3 using real-time polymerase chain reaction, and compared the results to expression levels in 6 healthy adult volunteers (controls). We also measured plasma cortisol as a well-known stress hormone. The expression of HSP70 mRNA in PBMCs was 2.1-fold higher on POD1 compared to the controls $(\mathrm{P}=0.041)$ and was positively correlated with TLR 4 mRNA $\left(r^{2}=0.45\right.$, $\mathrm{P}=0.0007)$. The expression of TNF- $\alpha$ mRNA tended to be lower on POD1 $(\mathrm{P}=0.055)$ and was significantly decreased on POD3 ( $\mathrm{P}=0.016)$, and iNOS mRNA were significantly lower on POD1 $(\mathrm{P}=0.0015)$ and POD3 $(\mathrm{P}=0.0003)$ compared to the controls. Moreover, there was a positive correlation between the expression of TLR4 mRNA and plasma cortisol levels $\left(r^{2}=0.24, \mathrm{P}=0.021\right)$. The expression of HSP70 mRNA in PBMCs in the early postoperative period was significantly
\end{abstract}

Correspondence to: Dr Hiroshi Morimatsu, Department of Anesthesiology and Resuscitology, Okayama University Graduate School of Medicine, Dentistry and Pharmaceutical Sciences, 2-5-1 Shikata-cho, Kita-ku, Okayama 700-8558, Japan

E-mail: morimatu@ms7.megaegg.ne.jp

Key words: peripheral blood mononuclear cells, real-time polymerase chain reaction, surgical stress, inflammatory response higher and positively correlated with TLR4 mRNA. This suggests that HSP70-TLR4 signaling has an important role in postoperative inflammatory responses. However, the expression of pro-inflammatory mediators, including TNF- $\alpha$ and iNOS mRNA, was significantly decreased postoperatively. This may be caused by the anti-inflammatory mechanism of cortisol. Our findings indicate that responses to surgical stress reflect simultaneous pro-inflammatory and anti-inflammatory responses, and are complex.

\section{Introduction}

Excessive inflammatory responses are often induced by surgical trauma that occurs after major surgery, such as esophagectomy. It has been reported that these inflammatory responses cause infectious complications and/or multiple organ failure $(1,2)$. The progression and interrelationship of mediators that are released, activated or suppressed after major surgery appear to play an important role in responses to surgical stress $(1,2)$.

Heat shock protein 70 (HSP70) is an intracellular, highly conserved protein that maintains homeostasis in cells by modulating protein-protein interactions and participating in the folding, assembly and translocation of intracellular proteins (3). Under normal physiological conditions, HSP70 is expressed at low levels; however, under stressful conditions, it is induced and released into the circulation from injured or stressed viable cells (4-6).

Extracellular HSP70 has been reported to bind to toll-like receptor 4 (TLR4) and to initiate signal transduction pathways (7). TLR4 signaling cascades converge on the transcription of nuclear factor- $\mathrm{\kappa B}(\mathrm{NF}-\mathrm{\kappa B})$ and result in the transcription of various pro-inflammatory cytokines, such as tumor necrosis factor- $\alpha$ (TNF- $\alpha$ ) and inducible nitric oxide synthase (iNOS) (8). However, the exact interactions and relationships among these mediators are unknown.

We hypothesized that after major surgery, such as esophagectomy, HSP70 activates TLR4 signaling, which may regulate the release of pro-inflammatory mediators, such as TNF- $\alpha$ and iNOS. Accordingly, the first aim of the 
present study was to measure changes in the expression of HSP70, TLR4, TNF- $\alpha$ and iNOS mRNA in the peripheral blood mononuclear cells (PBMCs) of patients undergoing esophagectomy using real-time polymerase chain reaction (RT-PCR), and to analyze the correlation between these mRNAs. In addition, we evaluated the association between these mRNAs and the levels of cortisol, a well-known stress hormone.

\section{Materials and methods}

Study population. The study group comprised 11 patients who were admitted to the ICU of Okayama University Hospital after esophagectomy with a thoracoabdominal procedure for malignant tumors. Patient demographics and intra- and postoperative variables were recorded. Blood samples were also collected from 6 normal healthy subjects (4 males, 2 females) as controls. The protocol was approved by the Ethics Committee of Okayama University Hospital and written informed consent was obtained from each patient before the study.

Blood samples. Blood (15 ml) was collected from each patient through an indwelling radial artery catheter on postoperative days (POD) 1 and 3. These samples were used for plasma analysis and the isolation of PBMCs. Blood (10.5 ml) was also collected from the 6 healthy adult volunteers for the isolation of PBMCs.

Sample preparation (plasma and PBMCs). Blood plasma was drawn off from $4.5 \mathrm{ml}$ of a patient's blood sample after using a centrifuge at $5,000 \mathrm{rpm}$ for $5 \mathrm{~min}$ and stored at $-80^{\circ} \mathrm{C}$ before plasma cortisol measurements. Plasma concentrations of cortisol were analyzed by a radioimmunoassay (SRL Inc., Tokyo, Japan).

Whole blood $(10.5 \mathrm{ml})$ was drawn into a heparinized collection tube and immediately processed for isolation of PBMCs. Subsequently, $3 \mathrm{ml}$ Mono-Poly Resolving Medium (DS Pharma Biomedical Co. Ltd., Osaka, Japan) was added to three tubes and $3.5 \mathrm{ml}$ undiluted blood was layered onto the medium. These samples were centrifuged at 1,468 rpm at room temperature for $20 \mathrm{~min}$. The plasma was removed and the fraction that contained PBMCs was drawn off into a clean tube. This fraction was centrifuged with $4.5 \mathrm{ml}$ of phosphatebuffered saline at 1,160 rpm for $12 \mathrm{~min}$. The media were removed and PBMCs were vortexed with $1 \mathrm{ml}$ TRI Reagent (Sigma, St. Louis, MO, USA). Samples were stored at $-80^{\circ} \mathrm{C}$ until RT-PCR analysis.

$R T-P C R$. Total RNA was isolated and purified from individual PBMCs with an RNeasy ${ }^{\mathrm{TM}}$ mini kit (Qiagen Inc., Valencia, CA, USA). cDNA was reverse transcribed from $5 \mu \mathrm{g}$ of total RNA with a Ready-To-Go ${ }^{\text {TM }}$ T-primed First-Strand kit (Amersham Biosciences, Piscataway, NJ, USA).

The cDNA solution was diluted 10-fold with DNase-free water. Templates were amplified in a $20-\mu 1$ reaction mixture containing $10 \mu \mathrm{l}$ SYBR Green detection (Takara Bio Inc., Shiga, Japan), 4.2 $\mu 1$ DNase-free water, $0.8 \mu 1$ each of forward and reverse primers and $5 \mu \mathrm{l}$ of diluted cDNA solution. Primer sequences are shown in Table I. RT-PCR analysis was performed using Light Cycler (Roche Diagnostics, Mannheim, Germany) with the following amplification conditions: $95^{\circ} \mathrm{C}$ for $10 \mathrm{sec}$ followed by 45 cycles of $5 \mathrm{sec}$ at $95^{\circ} \mathrm{C}$ and $20 \mathrm{sec}$ at $60^{\circ} \mathrm{C}$. To construct plasmid standards, each target was amplified by RT-PCR with the same primers for quantitative RT-PCR, and the product was subcloned into pCRII-TOPO (Invitrogen, Carlsbad, CA, USA). These plasmids were linearized by endonuclease digestion to avoid super-coiled structures. Concentrations of the plasmids were measured by spectrophotometry and absolute copy numbers of plasmids were calculated from the concentrations. Serial dilutions of each plasmid were amplified and quantitated by RT-PCR to generate a standard curve. The absolute copy number of each target cDNA in the samples was determined by correspondence with the standard curve. The expression of each cDNA was normalized to the expression of $\beta$-actin cDNA using the equation: expression value = copy number of each cDNA/copy number of $\beta$-actin cDNA. PCR specificity was confirmed by sequencing, gel electrophoresis and melting curve analysis.

Statistical analysis. Data are expressed as the mean \pm SEM. Differences were evaluated using the paired t-test or one-way analysis of variance (ANOVA) followed by the t-test. For correlation analysis, the Pearson correlation test was used. $\mathrm{P}<0.05$ was considered statistically significant.

\section{Results}

Patients. The demographic data and clinical characteristics of the patients are shown in Table II. The mean age of the patients was $60.8 \pm 1.9$ years, and most $(73 \%)$ were male. Eight patients $(73 \%)$ underwent both resection and reconstruction of the esophagus, while the remaining $3(27 \%)$ underwent only resection. The mean length of surgery was $477 \pm 35 \mathrm{~min}$ and the mean blood loss during surgery was $862 \pm 286 \mathrm{ml}$.

Inflammatory response. White blood cell (WBC) counts and C-reactive protein (CRP) levels are shown in Fig. 1. WBC counts were above normal range on both POD1 (8.6 $\pm 0.710^{3 /}$ $\left.\mathrm{mm}^{3}\right)$ and POD3 $\left(8.5 \pm 0.9103 / \mathrm{mm}^{3}\right)$, but there was no significant difference between days $(\mathrm{P}=0.96)$. By contrast, CRP was high on POD3 $(17.0 \pm 3.0 \mu \mathrm{g} / \mathrm{dl})$, and was significantly increased compared to POD1 $(7.0 \pm 1.1 \mu \mathrm{g} / \mathrm{dl})(\mathrm{P}<0.0016)$.

Expression of HSP70, TLR4, TNF- $\alpha$ and iNOS mRNA. Expression of HSP70 mRNA was 2.1-fold higher on POD1 compared to healthy adults (control) $(\mathrm{P}=0.041)$. However, this increased expression of HSP70 mRNA returned to control levels on POD3. Similar changes were observed in the expression of TLR4 mRNA, although these changes did not reach statistical significance. By contrast, the expression of both TNF- $\alpha$ mRNA and iNOS mRNA showed completely different patterns compared to the expression of HSP70 mRNA. Compared to the controls, lower expression of TNF- $\alpha$ mRNA on POD3 $(\mathrm{P}=0.016)$ and lower expression of iNOS mRNA both on POD1 $(\mathrm{P}=0.0015)$ and on POD3 $(\mathrm{P}=0.0003)$ were observed. Only the expression of TLR4 mRNA was positively correlated with the expression of HSP70 mRNA $\left(r^{2}=0.45\right.$, $\mathrm{P}=0.0007)$ (Figs. 2 and 3). 
Table I. Primer pairs used for polymer chain reaction amplification.

\begin{tabular}{|c|c|c|c|}
\hline Target cDNA & Accession no. & Primer sequence $\left(5^{\prime} \rightarrow 3^{\prime}\right)$ & Amplicon size (bp) \\
\hline \multirow[t]{2}{*}{$\beta$-actin } & NM_001101 & Forward: GTGGCATCCACGAAACTACC & \\
\hline & & Reverse: GTACTTGCGCTCAGGAGGAG & 197 \\
\hline \multirow[t]{2}{*}{ HSP70 } & NM_005345 & Forward: TGGAGTCCTACGCCTTCAAC & \\
\hline & & Reverse: ATGGGGTTACACACCTGCTC & 193 \\
\hline \multirow[t]{2}{*}{ TLR4 } & NM_138554 & Forward: AACCAAGAACCTGGACCTGA & \\
\hline & & Reverse: AAACTCTGGATGGGGTTTCC & 186 \\
\hline \multirow[t]{2}{*}{ TNF- $\alpha$} & NM_000594 & Forward: TCAGAGGGCCTGTACCTCAT & \\
\hline & & Reverse: GGAAGACCCCTCCCAGATAG & 220 \\
\hline \multirow[t]{2}{*}{ iNOS } & NM_000625 & Forward: TGCCAAGCTGAAATTGAATG & \\
\hline & & Reverse: CTTCTTCGCCTCGTAAGGAA & 115 \\
\hline
\end{tabular}

HSP70, heat shock protein 70; TLR4, toll-like receptor 4; TNF- $\alpha$, tumor necrosis factor- $\alpha$, iNOS, inducible nitric oxide synthase.

Table II. Patient characteristics.

\begin{tabular}{lc}
\hline Characteristic & Value \\
\hline Demographic & \\
Age (years) & $60.8 \pm 1.9$ \\
Female, n (\%) & $3(27)$ \\
Intraoperative & \\
Epidural catheter, n (\%) & $9(82)$ \\
Blood transfusion, n (\%) & $3(27)$ \\
Blood loss (ml) & $862 \pm 286$ \\
Procedure & \\
$\quad$ Resection, n (\%) & $3(27)$ \\
Resection + reconstruction, n (\%) & $8(73)$ \\
Anesthesia time (min) & $557 \pm 45$ \\
Surgery time (min) & $477 \pm 35$ \\
Postoperative & \\
Blood transfusion, n (\%) & $4(36)$ \\
Duration of mechanical ventilation (days) & $10.6 \pm 6.0$ \\
Pneumonia, n (\%) & $3(27)$ \\
Anastomotic leakage, $\mathrm{n}(\%)$ & $3(27)$ \\
ICU stay (days) & $16.1 \pm 6.3$ \\
\hline
\end{tabular}

Values represent the mean \pm SEM or percentage from 11 patients. ICU, intensive care unit.

Plasma concentration of cortisol. Plasma concentrations of cortisol remained within normal ranges $(4.0-18.3 \mu \mathrm{g} / \mathrm{dl})$ on POD1 $(13.1 \pm 2.8 \mu \mathrm{g} / \mathrm{dl})$ and POD3 $(17.0 \pm 2.6 \mu \mathrm{g} / \mathrm{dl})$. Plasma concentrations of cortisol were significantly correlated only with the expression of TLR 4 mRNA $\left(\mathrm{r}^{2}=0.24, \mathrm{P}=0.021\right)$ (Fig. 4).

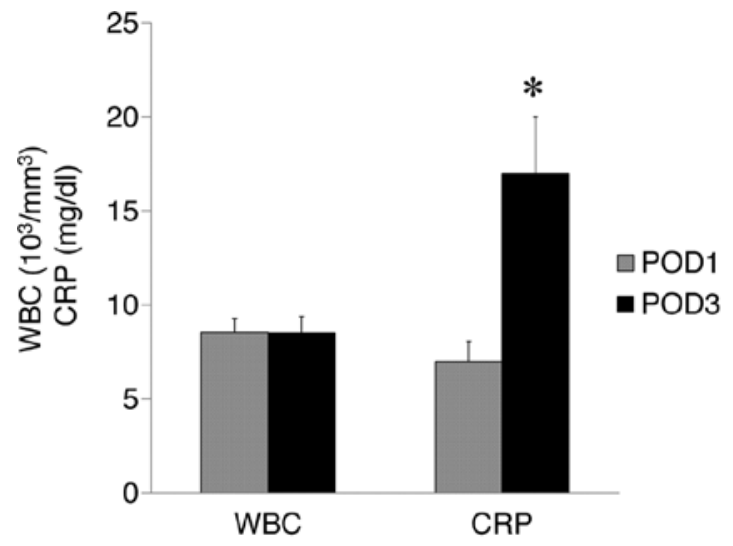

Figure 1. White blood cell counts (WBC) and C-reactive protein (CRP) levels in patients after undergoing esophagectomy. POD, postoperative day. Data are the mean \pm SEM. ${ }^{*} \mathrm{P}<0.01$ vs. POD1 (paired t-test).

\section{Discussion}

The present study demonstrated that, in PBMCs of patients undergoing esophagectomy with a thoracoabdominal procedure, the expression of HSP70 mRNA increased significantly on POD1 compared to healthy normal adults and was positively correlated with the expression of TLR4 mRNA. By contrast, mRNA expression of TNF- $\alpha$ and iNOS decreased significantly during the early postoperative period compared to healthy adults. Moreover, there was a positive correlation between the expression of TLR4 mRNA and plasma cortisol levels.

It is well known that HSP70 is induced and released from stressed cells in various situations, including after severe trauma (9) and acute myocardial infraction (10). Moreover, extracellular HSP70 plays a major role in the pro-inflammatory response by binding TLR4 $(7,11)$ and activates subsequent signaling cascades that converge on transcription factor $\mathrm{NF}-\kappa \mathrm{B}$, resulting in the up-regulation of the expression of 
A

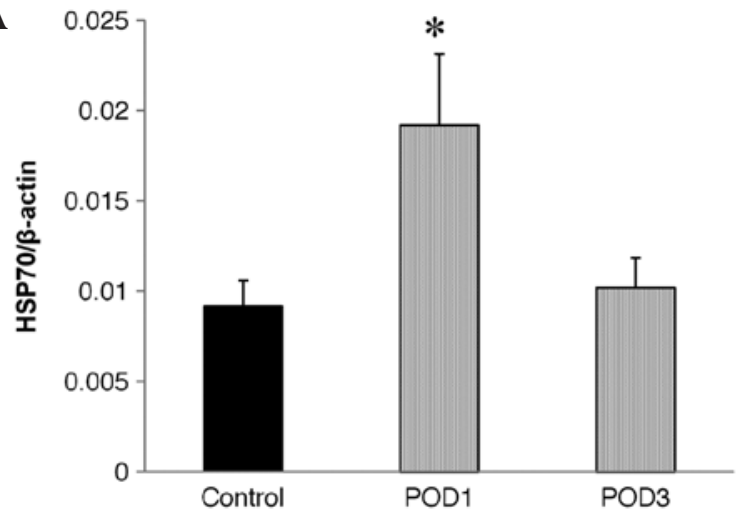

C

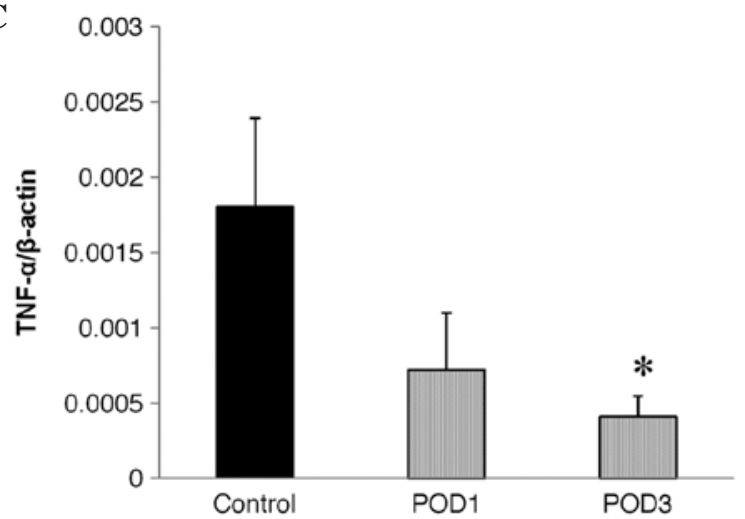

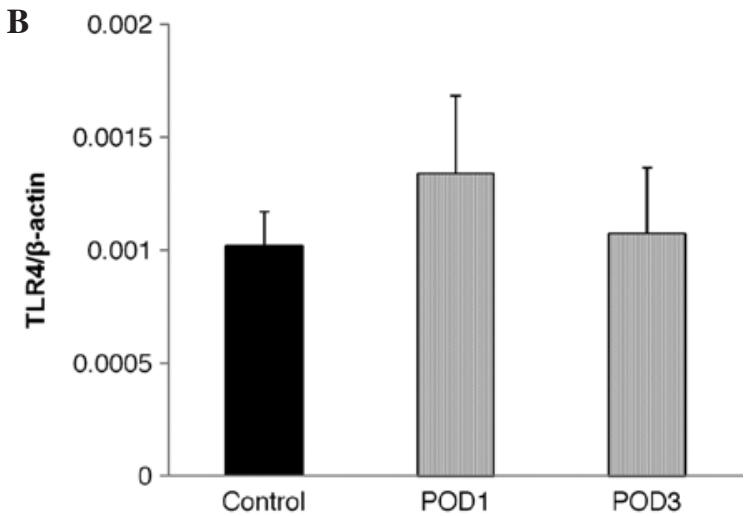

D

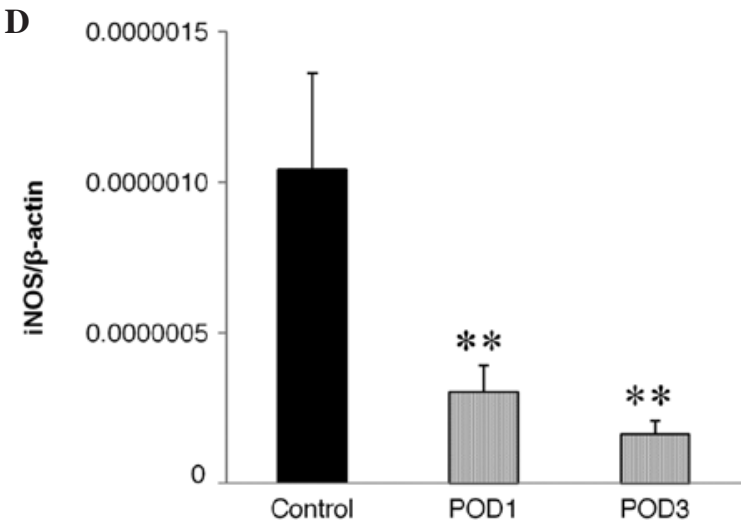

Figure 2. Expression of (A) heat shock protein 70 (HSP70), (B) toll-like receptor 4 (TLR4), (C) tumor necrosis factor- $\alpha$ (TNF- $\alpha$ ) and (D) inducible nitric oxide synthase (iNOS) mRNA. POD, postoperative day. Data are the mean \pm SEM. ${ }^{*} \mathrm{P}<0.05$ vs. the control group; ${ }^{* *} \mathrm{P}<0.01$ vs. the control group in post hoc tests (one-way analysis of variance).

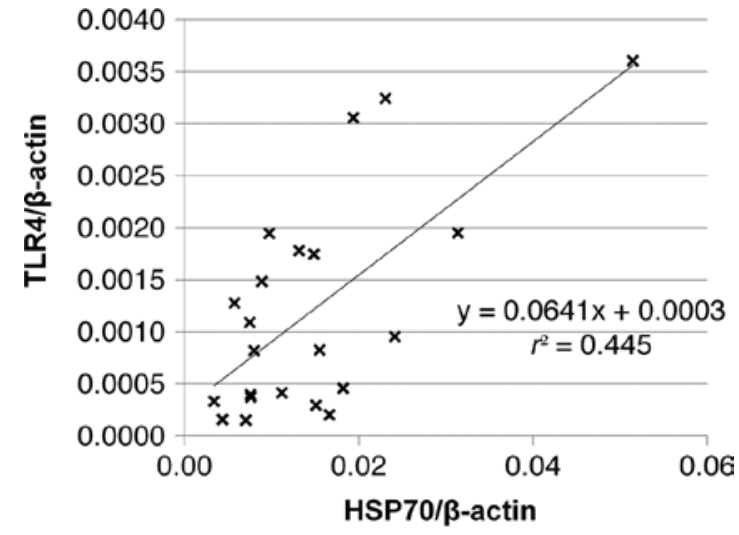

Figure 3. Correlation between the expression of heat shock protein 70 (HSP70) mRNA and toll-like receptor 4 (TLR4) mRNA.

pro-inflammatory mediators, including TNF- $\alpha$ and iNOS (8). This HSP70-TLR4 signaling mechanism has also been reported to occur in postoperative settings. Dybdahl et al reported that elevated systemic levels of HSP70 were detected in the plasma of patients and that the expression of TLR4 on monocytes was enhanced on POD1 after elective coronary artery bypass grafting (CABG) $(11,12)$. In the present study, the expression of HSP70 mRNA also significantly increased on POD1 and was positively correlated with TLR4 after

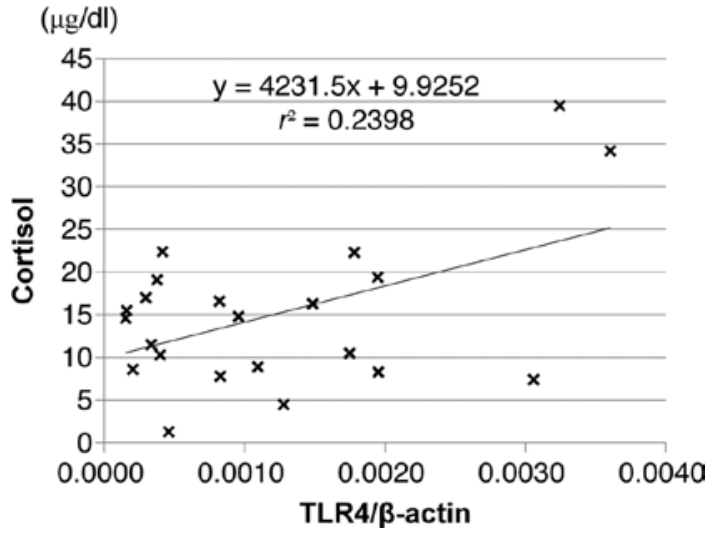

Figure 4. Correlation between the expression of toll-like receptor 4 (TLR4) mRNA and plasma cortisol levels.

esophagectomy. These findings suggest that stress-induced HSP70 was released outside the cells and played a significant role in activating the TLR4 signaling cascades during postoperative inflammatory responses, which is consistent with a previous study (12).

Although these pro-inflammatory responses are activated, some anti-inflammatory responses are also activated to establish a balance (13). Cortisol is an anti-inflammatory mediator (14) and suppresses the transcription of NF-кB (15). In the 
present study, plasma cortisol levels were positively correlated with the expression of TLR4 mRNA, indicating that cortisol may be produced to inhibit TLR4 signaling by suppressing the transcription of $\mathrm{NF}-\kappa \mathrm{B}$, resulting in a reduction of the expression levels of TNF- $\alpha$ and iNOS mRNA.

After major surgery, the initial systemic inflammatory response syndrome (SIRS) is mediated by pro-inflammatory mediators and progressively suppressed by the development of compensatory anti-inflammatory response syndrome (CARS) (16). However, in the present study, we failed to reveal a typical SIRS to CARS progression. Our findings indicate that, at the gene level, activation of the pro-inflammatory pathway and the anti-inflammatory response occurred simultaneously to restore homeostasis. The postoperative inflammatory cascade is multimodal and difficult to classify as SIRS or CARS based only on biomarker profiling.

There are two primary limitations of the present study. First, we did not measure the level of extracellular HSP70, and increased levels of HSP70 mRNA expression may reflect not only extracellular HSP70, but also intracellular HSP70. However, HSP70 is highly expressed in stressed cells and released into extracellular space (17). Previous research has indicated that elevated systemic levels of HSP70 in humans are present after elective CABG (12) and liver resection (18). Considering these investigations, increased levels of HSP70 mRNA potentially reflect the elevated levels of extracellular HSP70 in the postoperative setting.

The second limitation is that we compared patient postoperative data to healthy adult volunteers, but not to preoperative data. Since HSP70 and TNF- $\alpha$ are also induced by cancer stress (19), the expression of these mRNA in patient PBMCs may reflect cancer stress as well as surgical stress. However, we believe it is important to compare patients to healthy people, because normal ranges for these mRNA levels have not been identified, unlike those for usual inflammatory makers, such as WBCs and CRP.

Responses to surgical stress are complex and multimodal, and there is vast room for further research to elucidate the mechanism of postoperative inflammatory responses. Our findings indicate that HSP70-TLR4 signaling plays an important role in postoperative inflammatory responses. Further studies on various factors surrounding HSP70-TLR4 signaling are required to clarify the host response to surgical stress and to identify early markers of postoperative inflammatory responses. Moreover, subsequent investigations into the relationship between patient clinical states and the HSP70-TLR4 signaling mechanism may aid in the development of early diagnostics and therapies for postoperative inflammatory responses.

In conclusion, we showed that the expression of HSP70 mRNA was significantly higher on POD1 and positively correlated with TLR4 after esophagectomy. By contrast, TNF- $\alpha$ and iNOS mRNA decreased significantly, possibly due to the anti-inflammatory effects of cortisol. These findings indicate that both pro-and anti-inflammatory responses occur in the early postoperative period. HSP70-TLR4 signaling may play an important role in establishing a balance between proinflammatory and anti-inflammatory responses in the host after esophagectomy.

\section{References}

1. Angele MK and Chaudry IH: Surgical trauma and immunosuppression: pathophysiology and potential immunomodulatory approaches. Langenbecks Arch Surg 390: 333-341, 2005.

2. Menger MD and Vollmar B: Surgical trauma: hyperinflammation versus immunosuppression? Langenbecks Arch Surg 389: 475-484, 2004.

3. Pagel PS: Induction of heat shock protein 70 and preconditioning by sevoflurane: a potent protective interaction against myocardial ischemia-reperfusion injury. Anesth Analg 107: 742-745, 2008.

4. De Jong PR, Schadenberg AW, Jansen NJ and Prakken BJ: Hsp70 and cardiac surgery: molecular chaperone and inflammatory regulator with compartmentalized effects. Cell Stress Chaperones 14: 117-131, 2009 .

5. Hunter-Lavin C, Davies EL, Bacelar MM, Marshall MJ, Andrew SM and Williams JH: Hsp70 release from peripheral blood mononuclear cells. Biochem Biophys Res Commun 324: 511-517, 2004

6. Basu S, Binder RJ, Suto R, Anderson KM and Srivastava PK: Necrotic but not apoptotic cell death releases heat shock proteins, which deliver a partial maturation signal to dendritic cells and activate the NF-kappa B pathway. Int Immunol 12: 1539-1546, 2000.

7. Chase MA, Wheeler DS, Lierl KM, Hughes VS, Wong HR and Page K: Hsp72 induces inflammation and regulates cytokine production in airway epithelium through a TLR4- and NF-kappaB-dependent mechanism. J Immunol 179: 6318-6324, 2007.

8. Lee MS and Kim YJ: Signaling pathways downstream of patternrecognition receptors and their cross talk. Annu Rev Biochem 76: 447-480, 2007.

9. Pittet JF, Lee H, Morabito D, Howard MB, Welch WJ and Mackersie RC: Serum levels of Hsp 72 measured early after trauma correlate with survival. J Trauma 52: 611-617, 2002.

10. Dybdahl B, Slordahl SA, Waage A, Kierulf P, Espevik T and Sundan A: Myocardial ischaemia and the inflammatory response: Release of heat shock protein 70 after myocardial infarction. Heart 91: 299-304, 2005.

11. Asea A, Rehli M, Kabingu E, et al: Novel signal transduction pathway utilized by extracellular Hsp70: Role of toll-like receptor (TLR) 2 and TLR4. J Biol Chem 277: 15028-15034, 2002.

12. Dybdahl B, Wahba A, Lien E, et al: Inflammatory response after open heart surgery: release of heat-shock protein 70 and signaling through toll-like receptor-4. Circulation 105: 685-690, 2002.

13. Hiesmayr MJ, Spittler A, Lassnigg A, et al: Alterations in the number of circulating leucocytes, phenotype of monocyte and cytokine production in patients undergoing cardiothoracic surgery. Clin Exp Immunol 115: 315-323, 1999.

14. Yeager MP, Rassias AJ, Fillinger MP, et al: Cortisol antiinflammatory effects are maximal at postoperative plasma concentrations. Crit Care Med 33: 1507-1512, 2005.

15. Van Leeuwen HJ, van der Bruggen T, van Asbeck BS and Boereboom FT: Effect of corticosteroids on nuclear factorkappab activation and hemodynamics in late septic shock. Crit Care Med 29: 1074-1077, 2001.

16. Osuchowski MF, Welch K, Siddiqui $\mathrm{J}$ and Remick DG: Circulating cytokine/inhibitor profiles reshape the understanding of the SIRS/CARS continuum in sepsis and predict mortality. J Immunol 177: 1967-1974, 2006.

17. Asea A: Heat shock proteins and toll-like receptors. Handb Exp Pharmacol 183: 111-127, 2008.

18. Kimura F, Itoh H, Ambiru S, et al: Circulating heat-shock protein 70 is associated with postoperative infection and organ dysfunction after liver resection. Am J Surg 187: 777-784, 2004.

19. Leu JI, Pimkina J, Frank A, Murphy ME and George DL: A small molecule inhibitor of inducible heat shock protein 70. Mol Cell 36: 15-27, 2009. 